DOI 10. 18307/2018. 0626

(c) 2018 by Journal of Lake Sciences

\title{
云南高原渔洞水库鱼类空间分布格局及主要影响因子"
}

\author{
连玉喜 ${ }^{1,2,3}$, 李 昌 $^{1}$, 叶少文 ${ }^{1}$, 李 为 $^{1}$, 刘家寿 ${ }^{1}$, 李钟杰 ${ }^{1 * *}$ \\ (1: 中国科学院水生生物研究所, 淡水生态与生物技术国家重点实验室, 武汉 430072) \\ (2: 安庆师范大学水生生物保护与水生态修复安徽省高校工程技术研究中心, 安庆 246133) \\ (3: 安庆师范大学生命科学学院, 安庆 246133)
}

\begin{abstract}
摘 要: 鱼类控藻是常用的生物控藻技术之一, 其前提需明确水体中鱼类群落结构及分布特征. 为科学调整渔洞水库鱼 类群落结构,制定合理的生物操纵策略,2013 年 7 月运用 Simrad EY60 型分裂波束回声探测仪对该水库进行了水声学探 测, 在结合多网目复合刺网 (网目 $=8.5 、 4.0 、 12.5 、 2.0 、 11.0 、 1.6 、 2.5 、 4.8 、 3.1 、 1.0 、 7.5$ 和 $6.0 \mathrm{~cm}$ ) 取样的基础上, 研究了水库 鱼类群落结构及其空间分布特征, 并初步探讨了影响渔洞水库鱼类空间分布的关键因素. 调查中在渔洞水库共采集到鱼 类 5 科 12 种, 其平均密度为 $638.4 \pm 310.2 \mathrm{ind} . / 1000 \mathrm{~m}^{3}$. 鱼类在水库中呈不均匀分布, 库首、库中、库湾及库尾鱼类密度分 别为 $521.5 \pm 371.3 、 561.9 \pm 189.2 、 653.7 \pm 323.7$ 和 $1137.1 \pm 90.4 \mathrm{ind} . / 1000 \mathrm{~m}^{3}$, 呈逐渐增大趋势, 且库尾鱼类的平均个体要大 于库首、库中和库湾; 在垂直方向上, $97.6 \%$ 的鱼类都分布在水面以下 $0 \sim 10 \mathrm{~m}$ 的水层, 深度超过 $10 \mathrm{~m}$ 的水层, 鱼类所占比 例只有 $2.4 \% ; 0 \sim 20 \mathrm{~m}$ 水层鱼类的平均目标强度最大 $(-58.6 \mathrm{~dB}), 20 \sim 40 \mathrm{~m}$ 水层鱼类平均目标强度最小 $(-63.9 \mathrm{~dB})$. MRT 预测模型表明影响鱼类空间分布的关键环境因子为水温和水深. 基于渔洞水库的鱼类组成和空间分布特征, 建议一方面 加大鲢、鳙放养量, 另一方面从所属水系引进中上层土著肉食性鱼类来调整鱼类群落结构,控制藻类生物量.
\end{abstract}

关键词: 渔洞水库;水声学;生物操纵; 群落结构;空间分布; 环境因子

\section{Fish spatial distribution patterns and controlling factors in Yudong Reservoir, Yunnan Plateau}

\author{
LIAN Yuxi ${ }^{1,2,3}$, LI Chang ${ }^{1}$, YE Shaowen $^{1}$, LI Wei $^{1}$, LIU Jiashou ${ }^{1} \&$ LI Zhongjie $^{1 * *}$ \\ (1: State Key Laboratory of Freshwater Ecology and Biotechnology, Institute of Hydrobiology, Chinese Academy of Sciences, \\ Wuhan 430072, P.R.China) \\ (2: Research Center of Aquatic Organism Conservation and Water Ecosystem Restoration in Anhui Province, Anqing Normal \\ University, Anqing 246133, P.R.China) \\ (3: College of Life Science, Anqing Normal University, Anqing 246133, P.R.China)
}

Abstract: Understanding of fish community structure is the basis of determining appropriate strategy to control the alga bloom. To
regulate fish community structure scientifically and define a rational biomanipulation strategy, hydroacoustic investigation were car-
ried out in Yudong Reservoir with Simrad EY60 split-beam echo sounder in July of 2013 , accompanied with the sampling of Nordic
multi-mesh gill nets ( mesh-size $=8.5,4.0,12.5,2.0,11.0,1.6,2.5,4.8,3.1,1.0,7.5$ and $6.0 \mathrm{~cm}$ ). A total of 12 fish species
were collected and the density was $638.4 \pm 310.2 \mathrm{ind} . / 1000 \mathrm{~m}^{3}$. Fish distributed unevenly and its density tend to increase from dam
part, middle part, tributary part to upper part of the reservoir, with density of $521.5 \pm 371.3,561.9 \pm 189.2,653.7 \pm 323.7$,
$1137.1 \pm 90.4$ ind. $/ 1000 \mathrm{~m}^{3}$, respectively. Moreover, fish in the upper reservoir has a bigger size than that in other parts. The verti-
cal distribution pattern is: $97.6 \%$ fish habitat in the $0-10 \mathrm{~m}$ layer while there was only $2.4 \%$ fish distributed in waters deeper than
$10 \mathrm{~m}$, average target strength in the $0-20 \mathrm{~m}$ layer was highest $(-58.6 \mathrm{~dB})$ while the $20-40 \mathrm{~m}$ layer was lowest $(-63.9 \mathrm{~dB})$. The
Multivariate regression tree model indicates that temperature and water depth have significant impact on fish density. To control the

* 公益性行业(农业)科研专项经费(201303056)、中国长江三峡集团公司科研项目 (CT-12-08-01) 和淡水生态与生 物技术国家重点实验室项目 (2011FBZ28) 联合资助. 2017-10-24 收稿; 2018-01-26 收修改稿. 连玉喜( 1986 ) , 男, 博士, 讲师; E-mail: lianyx177@163.com.

** 通信作者; E-mail: zhongjie@ihb.ac.cn. 
algae bloom, we suggest to enhance stocking of Silver Carp and Bighead Carp, and to introduce endemic piscivorous fishes at the same time to regulate fish community.

Keywords: Yudong Reservoir; hydroacoustics; biomanipulation; community structure; spatial distribution; environmental factors

渔洞水库位于长江上游金沙江流域横江支流酒渔河正源的居乐河上, 属国家大二型水库, 是云南省库 容最大的水库之一, 是一座集城市供水、农业灌溉、防洪、发电、渔业等功能于一体的综合大型水利骨干工程. 但随着近年来库区周边社会经济的发展和污水排放的增加, 库区水体营养程度升高, 浮游植物大量增殖, 水 质不断下降, 直接威胁到昭通市的用水卫生安全 ${ }^{[1-4]}$. 水体中藻类的大量增殖会加速水体中营养物质循环和 富营养化进程, 一些藻类, 如微囊藻 (Microcystis)、直链藻 (Melosira) 和脆杆藻 (Fragilaria) 等藻类还能产生藻 毒素 ${ }^{[5-6]}$. 因此,要保证饮用水安全必须控制藻类的大量增殖.

鱼类控藻是常用的生物控藻技术之一, 具有环保、投人低和持续时间长的优点 ${ }^{[7]}$. 渔洞水库曾向水库中 投放了大量鲢、鳙, 意图以鲢、鲔的滤食来控制藻类丰度, 但效果不甚明显. 事实上, 生物操纵的有效实施必 须根据水环境及水生生物类群的特点, 因地制宜地对鱼类群落结构进行调整, 才能获得预期的效果. 渔洞水 库地处云南高原, 其水环境特征和鱼类群落结构有高原水域的独特之处. 因此, 通过生物操纵手段控制渔洞 水库浮游植物种群规模, 其前提必须明确鱼类群落结构及其资源利用现状, 据此对鱼类群落结构进行合理 调整. 渔洞水库属于深水水库,传统的鱼类资源调查方法在大型深水水库实施时存在费时费力、误差大等问 题, 水声学探测法作为一种新型评估方法能够提供连续数据, 并且具有高效快捷、不损伤调查对象和重复性 强等优点, 在国内外大水面鱼类行为及资源评估中得到广泛的应用 ${ }^{[8-10]}$. 因此, 本研究选择在浮游植物生物 量最高的季节, 以现代水声学作为主要手段, 研究渔洞水库鱼类空间分布特征, 在此基础上, 结合环境因子 取样分析影响鱼类时空分布的关键因子. 以期为高原富营养化水库制定科学的生物操纵策略、合理调整鱼 类群落结构提供科学参考.

\section{1 材料与方法}

\section{1 研究地点}

渔洞水库 $\left(27.395^{\circ} \sim 27.479^{\circ} \mathrm{N}, 103.475^{\circ} \sim 103.551^{\circ} \mathrm{E}\right)(1998$ 年建坝蓄水, 2000 年竣工, 地处云南省昭通 市西北面 $23 \mathrm{~km}$ 处, 图 1). 水库流域面积 $709 \mathrm{~km}^{2}$, 径流面积大, 主要人库河流有拦河、底罗河、龙树河、布初 河、瓜寨河、居乐河和新河, 水库补给系数为 $52.25^{[11]}$. 库区水面呈树枝状, 长度 $12.89 \mathrm{~km}$, 宽度 $300 \sim 400 \mathrm{~m}$, 面积 $13.6 \mathrm{~km}^{2}$. 最大水深 $105.3 \mathrm{~m}$, 平均水深 $38.4 \mathrm{~m}$, 兴利库容 $2.73 \times 10^{8} \mathrm{~m}^{3}$, 总库容量 $3.64 \times 10^{8} \mathrm{~m}^{3}[12]$.

渔洞水库自建库以来, 进行了鲢、鳙、鲤、鲫苗种投放, 并且向水库移植了陈氏新银鱼受精卵, 目前已形 成稳定种群.

\section{2 水声学探测}

通过水声学探测以获得鱼类的密度、个体大小组成和空间分布特征. 水声学探测选择在夜间开展, 因为 根据相关研究及本研究的预实验, 夜间鱼类个体更为分散,有利于获得单体回波 ${ }^{[13-16]}$. 具体探测时间为 2013 年 7 月 17 日 $21: 00-23: 20$ 和 7 月 18 日 20:45-22:20. 回声探测仪采用 Simrad 生产的 EY60,120 kHz 分裂 波束回声探测仪. 换能器 $-3 \mathrm{~dB}$ 波束为 $7^{\circ} \times 7^{\circ}$, 通过不锈钢制换能器支臂固定在探测船只右舷, 距离船首 $1 / 3$ 船体长度, 人水深度 $0.5 \mathrm{~m}$, 波束垂直向下发射. 通过 Garmin 60CSx 来实时确定探测位置, 回声探测仪与笔记 本电脑相连, 实时显示和存储数据. 探测之前采用标准校正球对换能器进行校正, 步骤按标准方法进行 ${ }^{[17]}$. ER60 数据采集程序所需要的水温和盐度等数据通过 YSI 6600V2 多参数水质监测仪测定. 调查时功率设定 $100 \mathrm{~W}$,脉冲宽度选择 $0.128 \mathrm{~ms}$, 脉冲发射频率设定为 5 pings $/ \mathrm{s}$.

调查船为水库巡逻艇, 全长 $6.0 \mathrm{~m}$, 宽 $2.1 \mathrm{~m}$, 功率 $110 \mathrm{Hp}$, 水声学探测时航速保持在 $6 \sim 8 \mathrm{~km} / \mathrm{h}$ 之间. 探 测实验从库尾的马渡口开始, 到大坝结束. 由于水库水面整体呈狭长型, 且岸线复杂, 采用 “之” 字形航线, 探 测水域覆盖水库主体和库湾, 总航程为 $36.7 \mathrm{~km}$ (图 1). 根据 Aglen 的定义 ${ }^{[18]}$, 该调查覆盖率为 9.9 , 达到 Doroszczyk 等 ${ }^{[19-20]}$ 建议关于获得可靠水声学评估结果的取样强度标准.

\section{3 鱼类群落及水环境调查}

通过鱼类群落调查以获得鱼类组成, 根据鱼类体长分布检验其与水声学探测信号等吻合度. 鱼类群落 


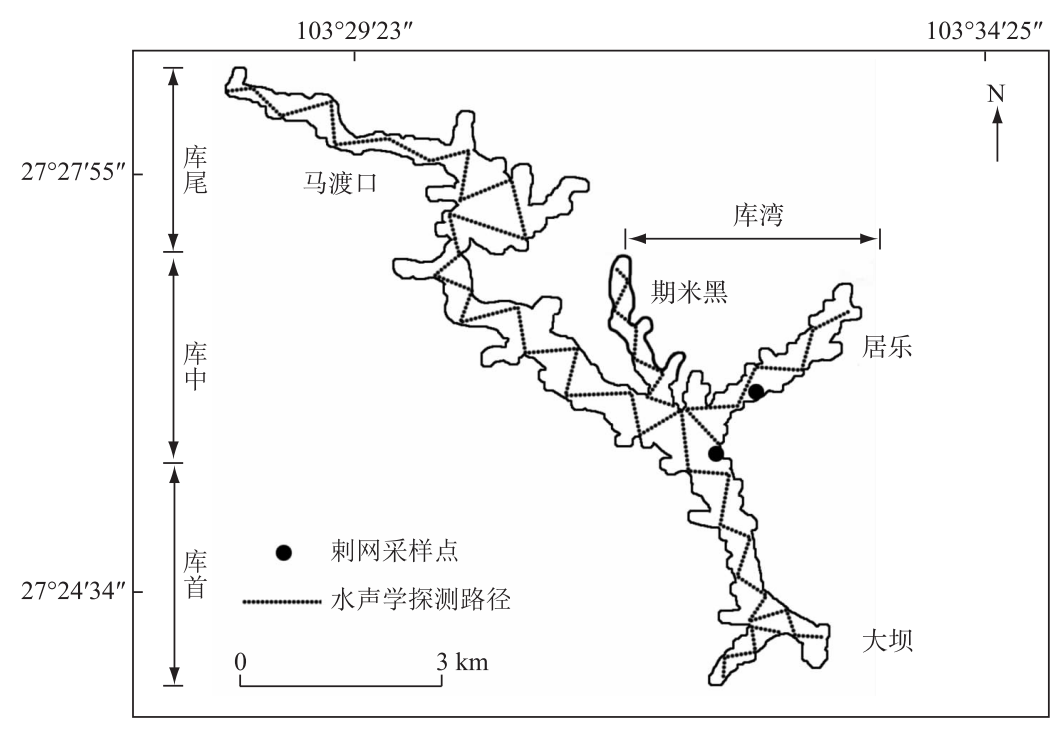

图 1 渔洞水库水声学探测路线

Fig.1 Routes of hydroacoustic survey in Yudong Reservoir

调查分别采用多网目复合刺网和三层刺网, 时间为 2013 年 7 月 17 日至 21 日. 多网目复合刺网主要针对小 型鱼类, 其规格为 $30 \mathrm{~m}$ (长) $\times 1.5 \mathrm{~m}$ (高), 网目 $=8.5 、 4.0 、 12.5 、 2.0 、 11.0 、 1.6 、 2.5 、 4.8 、 3.1 、 1.0 、 7.5$ 和 $6.0 \mathrm{~cm}$; 三层刺网主要针对大型鱼类, 其规格为 $160 \mathrm{~m}$ (长) $\times 5 \mathrm{~m}$ (高), 网目 $=6.0 、 8.0 、 10.0$ 和 $12.0 \mathrm{~cm}$. 多网目复合刺 网布设水域涵盖沿岸带和敞水区, 平行岸边布设, 每个样点布设 5 条刺网; 三层刺网布设在敞水区, 垂直岸 边布设,每个样点布设 2 条刺网. 当日下午 18:00-19:00 放网, 次日上午 6:00-7:00 收网. 采集后的渔获物 在新鲜状态下进行鉴定、测量和统计. 种类鉴定参照 《中国动物志》 ${ }^{[21-22]}$, 空间和营养生态位划分参照《云南 鱼类志 $\rangle^{[23-24]}$. 测量长度精确到 $1 \mathrm{~mm}$, 重量精确到 $0.1 \mathrm{~g}$.

水声学探测的同时进行水环境测量, 主要采用 YSI 6600V2 多参数水质监测仪, 其测量指标包括深度、水 温、 $\mathrm{pH}$ 、溶解氧、电导率、叶绿素等. 测量范围为 $0 \sim 60 \mathrm{~m}$, 纵向测量间隔约为 $1 \mathrm{~m}$. 水环境测量和水声学探测 同步进行,每个断面测量 2 处, 与鱼类空间分布相匹配,用来分析影响鱼类空间分布的关键环境因子.

\section{4 数据提取}

水声学数据采用 Echoview (ver. 5.2) 分析. 表层设定一条深度为 $1 \mathrm{~m}$ 的线排除来自表层的噪音,底线通 过 Echoview 软件的最优候选算法自动绘出,并根据需要进行人工修正,表层线以上和底线以下的区域被排 除分析. 此外, 一些明显的噪音, 譬如由船只螺旋桨或声呐所引起的噪声被定义为坏数据不予分析. 清理除 噪后的回声映像通过回声积分法分析, 水层厚度设定为 $10 \mathrm{~m}$, 以 400 pings 为一个积分单元, 长度约为 160 $\mathrm{m}$, 根据船速稍有变化; 垂直方向上, 以 $2 \mathrm{~m}$ 为一个水层. 为了计算鱼类密度, 首先创建一个新的单体回波的 回声映像, 用以产生计算平均目标强度 (Target Strength, TS) 所需的单体回波. 采用 “ single target detection split beam method 2” 来作单体回波检测, 用来判定单体回波检测 ( SED) 的参数如下: TS 阈值 $=-66 \mathrm{~dB}$; 脉冲 宽度决定水平 $=6 \mathrm{~dB}$; 最小标准脉宽 $=0.4$; 最大标准脉宽 $=1.5$; 最大波束补偿 $(2$ ways $)=6 \mathrm{~dB}$; 短轴角度最大 标准偏差 $=0.6$; 长轴角度最大标准偏差 $=0.6$.

\section{5 数据处理及分析}

采用 Pearson 相关分析检验鱼类密度与水温、水深、溶解氧、电导率、 $\mathrm{pH}$ 、叶绿素 $\mathrm{a}$ 浓度等环境因子的相 关性, 如果 $P<0.05$, 则呈显著相关. 同时采用多变量回归树 (Multivariate Regression Tree, MRT $)^{[25]}$ 构建鱼类 密度与水温、水深、溶解氧、电导率、 $\mathrm{pH}$ 、叶绿素 $\mathrm{a}$ 浓度之间的预测模型. MRT 根据解释变量将响应变量按照 递归划分的方法分成不同的群聚结构, 使得同一群聚结构内案例的差异尽可能小, 不同群聚结构内的差异 尽可能大. MRT 树的建立首先是将数据按一定算法分成两个子集, 然后按照递归划分的方法不断生长, 最后 
获得一棵尽可能大的树. 最后通过多重交叉验证 ( v-fold cross-validation $)^{[26]}$ 对“树”进行“剪枝”, 以防止过度 拟合. 本研究将 MRT 模型迭代次数设置为 100 次, 以确保模型所得结果并非随机获得. 本研究中所有模型 构建和统计分析全部在 $R^{[27]}$ 中完成,采用 $R$ 程序包“mvpart”与“MVPART wrap” ${ }^{[28]}$.

鱼类资源空间分布的建模采用 ArcGIS 10.2 软件. 将通过回声探测仪获取的鱼体密度、水深和 GPS 位点 信息导人 ArcGIS, 在将获得的数据栅格化后,基于反距离插值法绘制渔洞水库水底地形和鱼类水平分布图.

\section{2 结果}

\section{1 鱼类种类组成}

本次调查, 在渔洞水库共发现鱼类 12 种, 共计 2337 尾, 隶属 3 目 5 科 (表 1). 其中, 鲤科 8 种, 占总种数 的 $66.7 \%$ (表 1). 根据物种在渔获物中的数量和重量比例对其在群落中的地位和作用进行划分, 将数量或重 量比例大于 $20 \% 、 1 \% \sim 20 \%$ 和低于 $1 \%$ 依次定义为优势种、常见种和偶见种. 以此为标准, 鲢、鲔、麦穗鱼、中 华鰟鮍和粲为鱼类群落中的优势种; 鲇和草鱼在渔获物中的数量和重量比例均低于 $1 \%$, 为偶见种; 其余种 类皆为常见种 (表 1). 事实上, 由于陈氏新银鱼生活史周期较短, 种群规模随时间变动较快, 其在群落中的 优势地位随季节而变化.

表 1 渔洞水库鱼类群落种类组成及生态类型

Tab.1 Species composition and ecotypes of fish in Yudong Reservoir

\begin{tabular}{|c|c|c|c|c|c|c|}
\hline 鱼类群落 & $\begin{array}{l}\text { 空间 } \\
\text { 生态位 }\end{array}$ & $\begin{array}{l}\text { 营养 } \\
\text { 生态位 }\end{array}$ & $\begin{array}{c}\text { 复合刺网渔获 } \\
\text { 体长/mm }\end{array}$ & $\begin{array}{l}\text { 三层刺网渔 } \\
\text { 获体长/mm }\end{array}$ & $\begin{array}{l}\text { 数量 } \\
\text { 比例 } / \%\end{array}$ & $\begin{array}{c}\text { 重量 } \\
\text { 比例 } / \%\end{array}$ \\
\hline \multicolumn{7}{|l|}{ 鲤科 Cyprinidae } \\
\hline 鳙Aristichthys nobilis & 中、上层 & 滤食性 & - & $436 \sim 464$ & 1.20 & 56.00 \\
\hline 鲢 Hypophthalmichthys molitrix & 中、上层 & 滤食性 & - & $368 \sim 528$ & 0.47 & 26.46 \\
\hline 鲤 Cyprinus carpio & 下层 & 杂食性 & - & $196 \sim 224$ & 0.21 & 1.28 \\
\hline 鲫 Carassius auratus & 中、下层 & 杂食性 & $144 \sim 186$ & - & 0.30 & 1.38 \\
\hline 草鱼 Ctenopharyngodon idellus & 中、下层 & 草食性 & - & $219 \sim 448$ & 0.17 & 0.95 \\
\hline 麦穗鱼 Pseudorasbora parva & 中、下层 & 杂食性 & $43 \sim 78$ & - & 42.36 & 3.17 \\
\hline 中华鳑鲏 Rhodeus ocellatus & 中、下层 & 碎屑食性 & $46 \sim 86$ & - & 24.56 & 3.55 \\
\hline 粲 Hemiculter leucisculus & 上层 & 杂食性 & $72 \sim 217$ & - & 20.50 & 6.54 \\
\hline \multicolumn{7}{|l|}{ 银鱼科 Salangidae } \\
\hline 陈氏新银鱼 Neosalanx taihuensis & 上层 & 浮游动物食性 & $36 \sim 52$ & - & 2.52 & 0.08 \\
\hline \multicolumn{7}{|l|}{ 鲇科 Siluridae } \\
\hline 鲇 Silurus asotus & 底层 & 肉食性 & - & $109 \sim 180$ & 0.09 & 0.11 \\
\hline \multicolumn{7}{|l|}{ 塘鳢科 Eleotridae } \\
\hline 小黄黝鱼 Micropercops swinhonis & 底层 & 杂食性 & $48 \sim 66$ & - & 1.93 & 0.11 \\
\hline \multicolumn{7}{|l|}{ 吻虾虎鱼科 Gobiidae } \\
\hline 子陵吻虾虎鱼 Rhinogobius giurinus & 底层 & 肉食性 & $52 \sim 61$ & - & 5.69 & 0.37 \\
\hline
\end{tabular}

\section{2 刺网渔获及水声学信号判别}

刺网渔获鱼体全长范围为 36 528 mm, 鱼体长度峰值出现在 $50 \mathrm{~mm}$ 左右, 随鱼体长度增加, 其在渔获中 的数量比例迅速降低, $96.3 \%$ 的鱼类全长都低于 $110 \mathrm{~mm}$. 鱼体目标强度先升高再降低, 在 $-62 \mathrm{~dB}$ 附近呈现峰 值. 50 330 mm 的鱼体长度分布与声学信号大于 $-62 \mathrm{~dB}$ 的部分具有很好的吻合度 (图 2). 二者的差异主要 在于体长小于 $50 \mathrm{~mm}$ 和目标强度小于 $-62 \mathrm{~dB}$ 的部分, 这是可被声学探测而不能被刺网捕获的部分. 根据刺 网取样的结果, 调查时渔洞水库中陈氏新银鱼体长为 $36 \sim 52 \mathrm{~mm}$, 由此推测水声学探测 $-66 \sim-62 \mathrm{~dB}$ 的声学 信号大部分来自于这部分体长的陈氏新银鱼.

刺网渔获中, 鲢、鳙的体长为 $368 \sim 528 \mathrm{~mm}$, 渔获物中鲤、草鱼的体长也在此范围, 但鲤和草鱼在渔获物 中的数量比例仅为 $0.38 \%$. 按照 Frouzova 等 ${ }^{[29]}$ 建立的有鳔鱼类目标强度一体长经验公式 “ TS $=23.9 \lg (10 T L)-$ 
103.9 ”换算, $370 \mathrm{~mm}$ 对应的目标强度约为 $-42 \mathrm{~dB}$, 因此可将大于 $-42 \mathrm{~dB}$ 的信号判定为鲢、鳙.

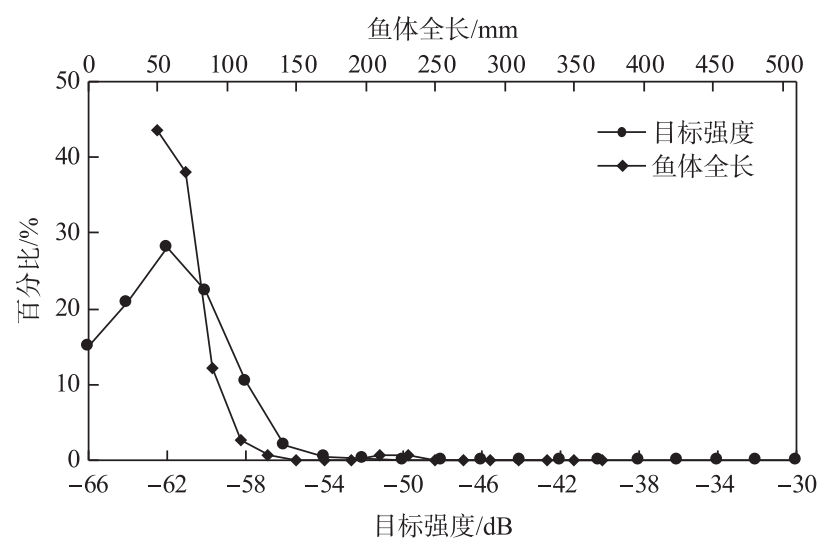

图 2 鱼体目标强度分布及刺网渔获鱼体全长分布

Fig.2 Frequency distribution of target strength and fish total length from gillnet catches

\section{3 鱼类水平分布格局}

根据水声学探测的结果, 渔洞水库鱼类 $(-66 \mathrm{~dB}<\mathrm{TS}<-30 \mathrm{~dB})$ 在空间上呈不均匀分布, 全库的鱼体密度 范围为 $8.9 \sim 2807.5$ ind. $/ 1000 \mathrm{~m}^{3}$, 均值为 $638.4 \pm 310.2 \mathrm{ind} . / 1000 \mathrm{~m}^{3}$ (图 3). 根据水域划分的结果, 库首、库 中、库湾和库尾的鱼类密度依次为 $521.5 \pm 371.3 、 561.9 \pm 189.2 、 653.7 \pm 323.7$ 和 $1137.1 \pm 90.4 \mathrm{ind} . / 1000 \mathrm{~m}^{3}$, 鱼 类密度呈逐渐增大的趋势. 鱼类主要集中在两处水域, 一处是库尾, 另一处位于期米黑和居乐两条支流库湾 与库区干流的交汇处,这两处水域的鱼类密度都超过了 1000 ind. $/ 1000 \mathrm{~m}^{3}$ (图 3). 同一水域,不同探测断面 的鱼类密度也存在差异, 库首、库中和库湾各调查断面间鱼类密度的差异要远远高于库尾, 表明库尾不仅具 有更高的鱼类密度,分布也更为均匀.
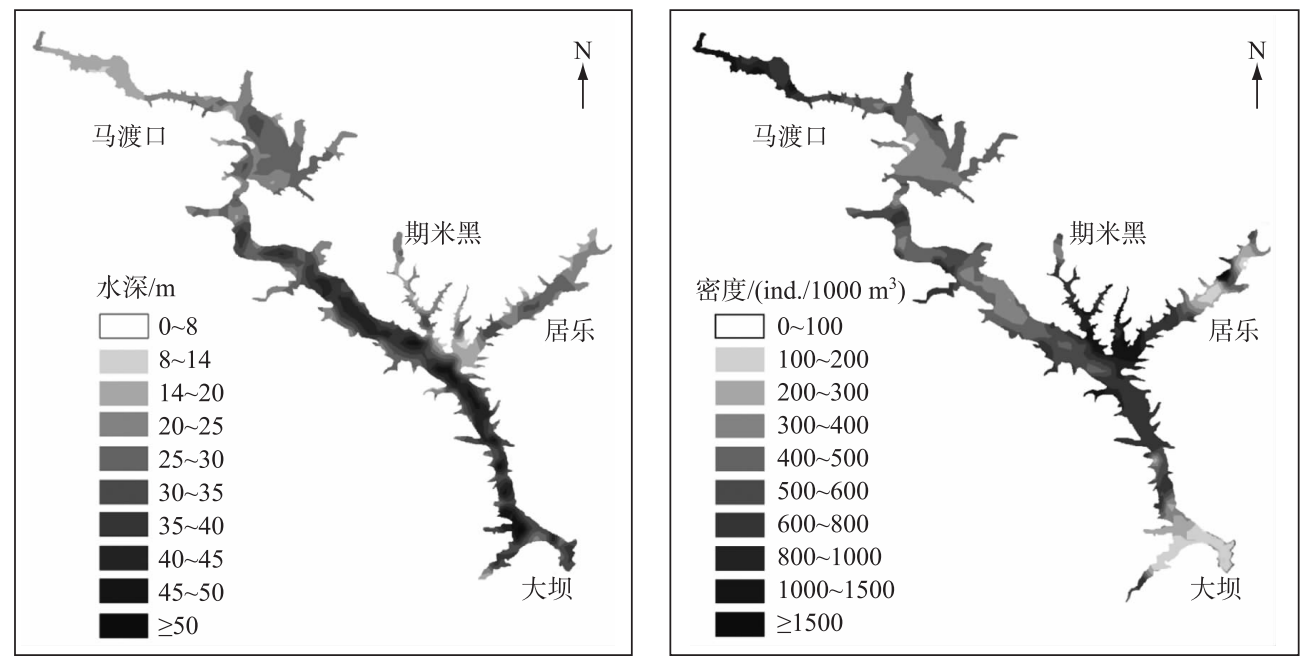

图 3 渔洞水库水底地形及鱼类水平分布

Fig.3 Bathymetric map and horizontal distribution of fish in Yudong Reservoir

在水平分布上, 库区不同水域的鱼类个体大小也存在差异. 库首、库中、库湾和库尾鱼类的平均 TS 分别 为 $-59.4 、-60.0 、-60.2$ 和 $-57.9 \mathrm{~dB}$, 按照 Frouzova 等 ${ }^{[29]}$ 的经验公式换算, 其对应体长分别为 $73 、 69 、 67$ 和 84 $\mathrm{mm}$. 这表明库首、库中和库湾鱼类大小组成相似, 库尾大个体鱼类所占的比例要高于库首、库中和库湾. 


\section{4 鱼类垂直分布格局}

以 $2 \mathrm{~m}$ 为一个水层, 分别计算出库首、库中、库尾和库湾不同水层鱼类密度占整个水柱鱼类密度之和的 比例. 结果表明, 库首、库中、库尾和库湾的鱼类在垂直方向上都显示出相同的分布格局, 鱼类基本上都分布 在水面以下 $10 \mathrm{~m}$ 以内的水层, 超过 $97.6 \%$ 的鱼类都分布在该水层, 深度超过 $10 \mathrm{~m}$ 的水域, 鱼类所占比例仅 为 $2.4 \%$, 密度不超过 $89.1 \mathrm{ind} . / 1000 \mathrm{~m}^{3}$; 并且在表层以下 $10 \mathrm{~m}$ 以内的水层, 随着水深增加, 鱼类密度呈逐渐 降低的趋势. 但不同水域鱼类在垂直方向的分布格局上存在着差异, 库尾和库湾鱼类的分布更最贴近水面, 其表层以下 $0 \sim 5 \mathrm{~m}$ 深度鱼类所占的比例分别为 $87.1 \%$ 和 $78.9 \%$, 要高于库首和库中的 $72.2 \%$ 和 $62.2 \%$. 这可 能是由于库尾和库湾平均深度较浅, 鱼类更贴近水面, 所以表层水域鱼类密度在整个水柱中的比例更高 (图4).

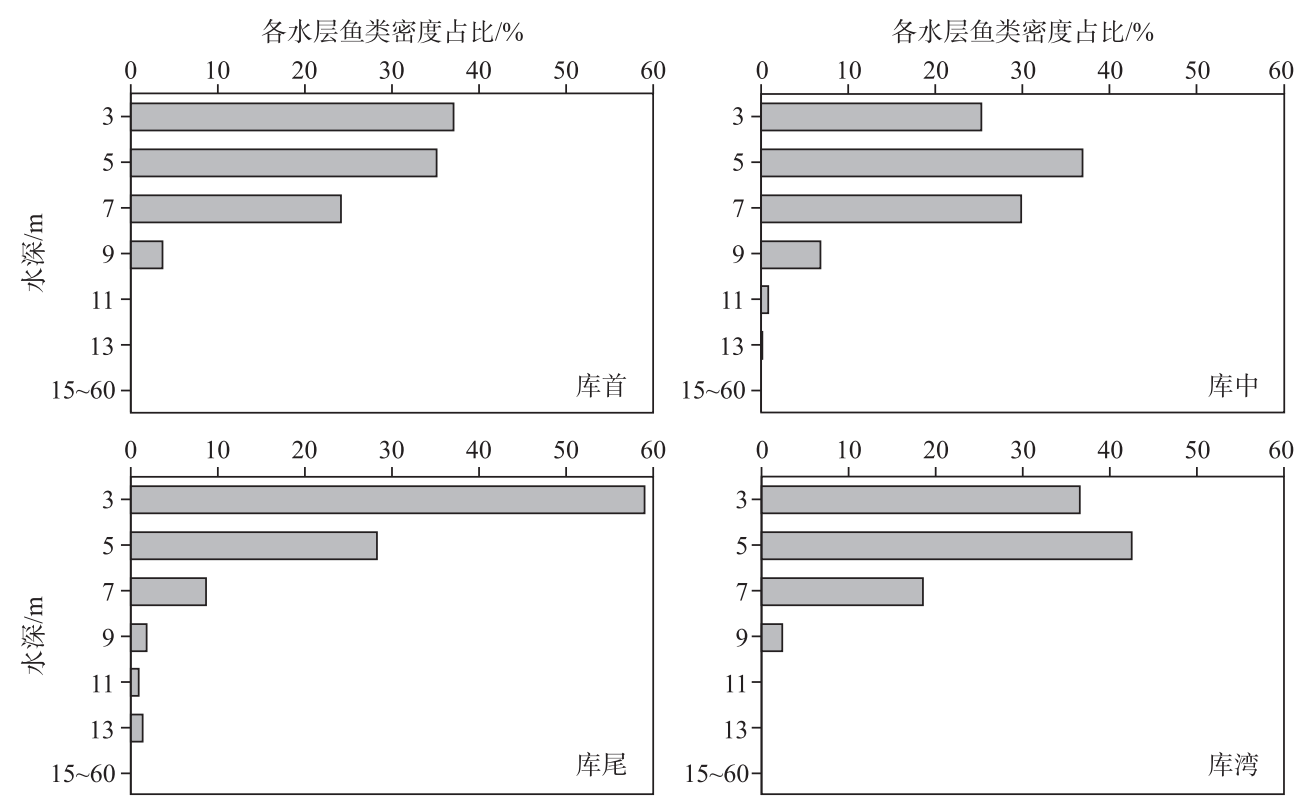

图 4 鱼类垂直分布格局 (柱状图表示各水层鱼类密度占整个水柱鱼类密度总和的百分比)

Fig.4 Fish vertical distributions ( The percentage was received as the

ratio between fish density in each of the layer and summation of all layers multiplied by 100)

不同水层鱼类个体大小的分布规律为: $0 \sim 20 \mathrm{~m}$ 水层鱼类的平均 TS 最大 $(-58.6 \mathrm{~dB})$, 其次是超过 $40 \mathrm{~m}$ 深度的水层, 平均 TS 为 $-62.6 \mathrm{~dB} ; 20 \sim 40 \mathrm{~m}$ 水层鱼类平均 TS 最小 $(-63.9 \mathrm{~dB})$. 这表明渔洞水库中较大个体 的鱼类分布于水体表层, 随着水深增加, 鱼类个体减小, 但在接近水底的深水层, 鱼类个体又逐渐增大. 其原 因在于, 个体较大的鲢、鳙和草鱼分布于水体表层, 而耐低氧的鲇栖息于水底, 其个体也较大, 这些个体较大 的鱼类提高了各自水层的平均 TS.

\section{5 鱼类分布与环境因子的关系}

Pearson 相关分析表明, 影响渔洞水库鱼类分布最重要的环境因子为溶解氧、水温和水深, 其中溶解氧、 水温与鱼类密度均呈显著正相关, 水深则与鱼类密度呈显著负相关, 这主要是由于水温和溶解氧受水深影 响, 其与水深呈显著负相关, 尤其是库首和库中水深较大的水域 (图 5); 电导率和叶绿素 a 浓度与鱼类密度 也均呈一定的相关性; $\mathrm{pH}$ 与鱼类密度无显著相关性 (表 2).

MRT 模型构建了一个有 4 个终端节点的预测树 (图 6). 本研究中, MRT 树所选环境因子解释了 $87.6 \%$ 的变量, 表明预测效果较好. 根据 MRT 树, 所有的 173 个水体单元主要依据水温和水深被聚类成 A、B、C 和 D 四个群聚(图 6), 分别包含 $126 、 6 、 25$ 和 16 个水体单元. 从 MRT 树的分类结果来看, 水温是影响鱼类密度 的主要环境因子, 能解释 $83.5 \%$ 的变量, 水温低于 $19.0^{\circ} \mathrm{C}$ 的 126 个水体单元, 鱼类平均密度为 $2.76 \mathrm{ind} . / 1000$ 
$\mathrm{m}^{3}$; 水温高于 $19.0^{\circ} \mathrm{C}$ 的 47 个水体单元,鱼类平均密度超过 817 ind. $/ 1000 \mathrm{~m}^{3}$; 其次是水深, 共解释了 $3.8 \%$ 的 变量.

表 2 鱼类密度与各环境因子的 Pearson 相关关系

Tab.2 Pearson correlation between environmental parameters and fish density

\begin{tabular}{|c|c|c|c|c|c|c|c|}
\hline 相关系数 & 鱼类密度 & 水温 & 电导率 & 溶解氧 & 水深 & $\mathrm{pH}$ & 叶绿素 a 浓度 \\
\hline 鱼类密度 & 1.000 & & & & & & \\
\hline 水温 & $0.758^{* *}$ & 1.000 & & & & & \\
\hline 电导率 & $0.767^{*}$ & $0.985^{* *}$ & 1.000 & & & & \\
\hline 溶解氧 & $0.866^{* *}$ & $0.894^{* *}$ & $0.886^{* *}$ & 1.000 & & & \\
\hline 水深 & $-0.649^{* *}$ & $-0.920^{* *}$ & $-0.884^{* *}$ & $-0.795^{* *}$ & 1.000 & & \\
\hline $\mathrm{pH}$ & -0.466 & -0.430 & -0.410 & -0.604 & 0.425 & 1.000 & \\
\hline 叶绿素 a 浓度 & $0.597^{*}$ & $0.920^{* *}$ & $0.897^{* *}$ & $0.744^{* *}$ & $-0.986^{* *}$ & -0.549 & 1.000 \\
\hline
\end{tabular}

*表示 $P<0.05 ; * *$ 表示 $P<0.01$.
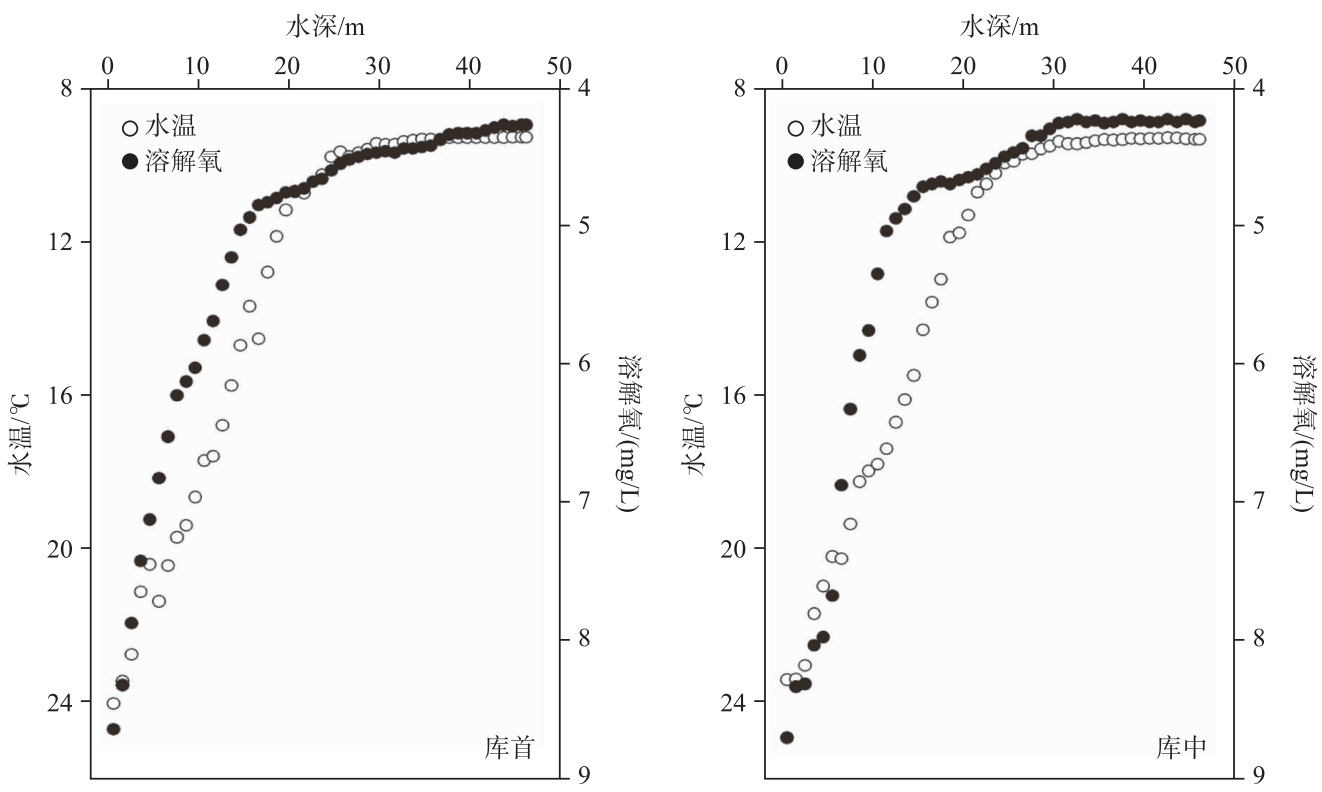

图 5 渔洞水库库首和库中水温、溶解氧垂向分布

Fig.5 Vertical distribution of water temperature and dissolved oxygen in dam part and middle part of Yudong Reservoir

\section{3 讨论}

\section{1 鱼类群落结构现状分析}

根据本次调查和渔洞水库管理处的标本信息, 渔洞水库仅有 12 种鱼类 (表 1). 从群落结构稳定性来看, 渔洞水库鱼类群落营养结构简单, 各营养级, 尤其是次级消费者种类贫乏. 结构过于简单的群落在受到外界 干扰后很容易发生逆行演替. 从鱼类控藻的角度看, 渔洞水库小型鱼类所占比例过高, 水声学探测结果显示 目标强度低于 $-56 \mathrm{~dB}$ 鱼类所占的比例达到 $98.5 \%$, 根据 Frouzova 等 ${ }^{[29]}$ 的研究公式, 该目标强度对应的鱼体 全长不超过 $100 \mathrm{~mm}$; 刺网渔获物中, 鱼体全长小于 $100 \mathrm{~mm}$ 的鱼类比例达到 $93.7 \%$, 麦穗鱼、中华鰟鲏、粲、小 黄䵢鱼和子陵吻虾虎鱼等小型鱼类比例达到 95.1\% (表 1). 此外, 渔洞水库银鱼种群也很大, 2010 年之前, 


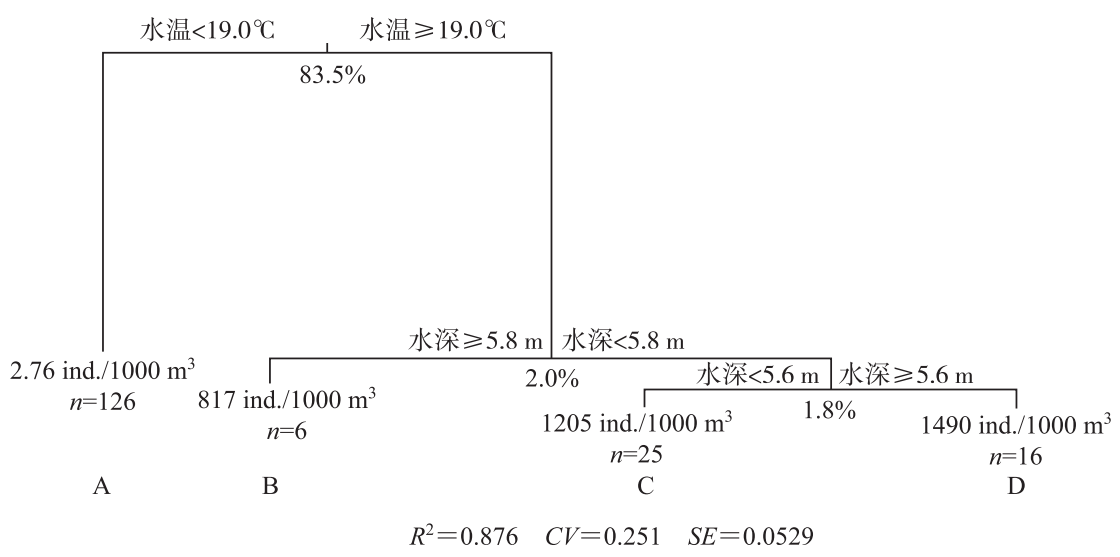

图 6 鱼类分布与环境因子关系 MRT 预测模型

Fig.6 Fish distribution patterns related with environmental factors which defined by MRT model

年均捕捞量超过 25 吨. 浮游动物是小型鱼类的重要摄食对象 ${ }^{[30-31]}$, 而浮游动物又以浮游植物作为食物, 因 此, 小型鱼类数量过多不利于对浮游植物的控制. 其次是大型凶猛性鱼类缺失, 仅有鲇一种, 其在渔获物中 比例也极低, 重量占比仅为 $0.11 \%$; 此外, 鲇与小型鱼类在空间生态位上存在差异, 因此, 无论从能量转化效 率还是空间生态位来看, 鲇种群均不足以对小型鱼类产生有效控制. 目前渔洞水库的鱼类群落结构不利于 鱼类控藻技术的开展.

\section{2 鱼类水平分布的影响因素}

在水平方向上, 库首、库中、库湾和库尾鱼类密度呈逐渐增大的趋势; 鱼类主要集中在库尾以及支流库 湾与库区干流的交汇处. 渔洞水库中, 影响鱼类空间分布的首先是水温, 鱼类基本都分布在水温高于 $19.0^{\circ} \mathrm{C}$ 的水层. 由于水温随水深增大而降低, 二者呈显著的负相关关系 (表 2), 并且渔洞水库从库首、库中、库湾到 库尾, 平均水深依次降低. 因此, 随着远离大坝, 鱼类密度呈逐渐上升的趋势 (图 3). 其他学者的研究也表明 水库鱼类密度会随着远离大坝、接近支流而上升 ${ }^{[32]}$.

水体中, 鲤科鱼类的密度会随着水体营养水平升高而增大 ${ }^{[33-34]}$, 因为高的营养水平意味着更丰富的饵 料资源. 在渔洞水库中, 从库尾、库湾、库中到库首, 水体营养盐水平依次降低 ${ }^{[35]}$, 鲤科鱼类的数量比例达到 89.77\% (表 1). 从生境类型和异质性来看, 库尾和支流更接近河流生境, 是产漂流性卵和粘性卵鱼类的重要 产卵场所 ${ }^{[36]}$, 大量的仔稚鱼使得这些水域具有更高的鱼类密度. 从库首到库尾、库湾, 生境异质性逐渐升 高, 而高的生境异质性有助于维持更高的物种多样性和物种丰富度. 因此, 从库首、库中、库湾到库尾, 渔洞 水库鱼类密度呈逐渐增大的趋势.

\section{3 鱼类垂直分布的影响因素}

渔洞水库鱼类垂直分布的主要影响因子是水温和水深. 鱼类缺乏调节体温的能力, 其体温随着环境水 温的变化而发生改变, 并对温度变化产生有限的适应, 大多数温水性鱼类适宜生长的水温为 $20 \sim 30^{\circ} \mathrm{C}$, 水温 过高或过低都会对鱼类的生长活动产生影响 ${ }^{[37]}$. 根据年人库水量和库容判断, 渔洞水库属于稳定的水温分 层型水库 ${ }^{[38]}$, 此次调查也证实渔洞水库存在稳定的热分层现象. 当水深超过 $15 \mathrm{~m}$ 时, 水温迅速降低到 $14^{\circ} \mathrm{C}$ 以下, 尤其是库首和库中 (图 5). 因此大多数鱼类会选择远离温跃层以下的水层, 而作为大多数鱼类食物的 浮游动物, 基本都分布在温跃层以上的水层. 根据 Brosse 等 ${ }^{[39]}$ 的研究, 温度和水深是决定夏季 Pareloup 湖鱼 类生境选择的主要环境因子. 根据水声学调查的结果, 渔洞水库大多数鱼类分布在水面以下 $10 \mathrm{~m}$ 以内的水 层, 并且随着水深增加, 鱼类密度逐渐降低. 该研究结果与 Prchalova 等 ${ }^{[32]}$ 的研究结论呈现出一致性, 在 Rimov 水库中, 深度对鱼类群落的影响最为显著, 鱼的种类、密度和生物量都随深度增加迅速减少. 在一些大 型河流中, 深度也是影响鱼类分布的关键环境因子 ${ }^{[40]}$. 在溶解氧充足的情况下, 鱼类的垂直分布格局受水 深的影响更大, 譬如, 在溶解氧相同时佩坦真䰻 (Dorosoma petenense) 倾向于选择浅的水层 ${ }^{[41]}$. 
渔洞水库中溶解氧浓度随水深增大而降低, 二者也呈显著的负相关关系 (表 2). 呼吸是鱼类生命活动 的基础, 只有在溶解氧充足的环境中, 鱼类才能进行正常的呼吸作用. 鱼类会主动迁移以避开低氧或缺氧水 体, 如季克斯湾的白鮏, 平时栖息于离岸较远的深水区域, 尽管该水域䎴料生物丰富, 但溶解氧浓度低, 因此 它们会定期向近岸洄游 ${ }^{[42]}$. 渔洞水库由于水交换率较低 ${ }^{[38]}$, 随着水深的增加, 溶解氧浓度会逐渐降低, 当超 过水面以下 $15 \mathrm{~m}$ 时, 溶解氧浓度降至 $5 \mathrm{mg} / \mathrm{L}$ 以下 (图 5). 根据 Prchalova 等 ${ }^{[32]}$ 在 Rimov 水库的研究, 溶解氧 是决定鱼类在垂直方向分布格局的关键环境因子, 大多数鱼类会避开溶解氧浓度低于 $5 \mathrm{mg} / \mathrm{L}$ 的水层. 因 此, 在渔洞水库中, 由于水体中下层溶解氧水平不能满足大多数鱼类的呼吸活动, 所以溶解氧也是影响渔洞 水库鱼类垂直分布的环境因子.

\section{4 生物操纵实施建议}

利用生物操纵 (Biomanipulation) 来控藻通常有两种途径:一是经典生物操纵, 通过增加食鱼性鱼类的数 量使浮游动物数量增加, 从而提高其对浮游植物的摄食效率, 降低浮游植物的数量 ${ }^{[43-44]}$; 二是非经典生物操 纵, 通过放养滤食性鱼类直接控制浮游植物数量 ${ }^{[45-46]}$. 这两种途径可以单独使用, 也可以结合起来使用, 具 体根据水体的实际情况而定. 通过水声学进行评估, 渔洞水库的滤食性鲢、鳙的生物量约为 $380 \mathrm{~kg} / \mathrm{hm}{ }^{2}$, 这 种生物量水平尚不足以达到完全控制藻类大量增殖的水平 ${ }^{[45]}$. 其次, 小型鱼类在渔洞水库鱼类群落中占据 了很高比例, 麦穗鱼、中华鰟鲏和粲在渔获物中的数量比例达到了 $87.42 \%$ (表 1 ); 而在声学信号中, 目标强 度小于 $-56 \mathrm{~dB}$ (根据公式 “ $T S=23.9 \lg (10 T L)-103.9$ ”, 该目标强度对应的鱼体全长不超过 $100 \mathrm{~mm})$ 的声学 信号占到了 $98.9 \%$ ( 图 2), 这些信号大部分来自于陈氏新银鱼、麦穗鱼、中华鰟鲏和粲等小型鱼类. 浮游动物 是小型鱼类的重要摄食对象 ${ }^{[30]}$, 因此小型鱼类数量过多会给浮游动物种群造成极大的捕食压力, 从而不利 于其对浮游植物种群规模的控制. 因此, 要控制渔洞水库浮游植物的大量增殖, 在加大非经典生物操纵的基 础上, 还必须实施经典生物操纵. 调整鱼类群落结构, 通过放养食鱼性鱼类控制小型鱼类的种群规模, 并使 其转化为优质的水产资源. 渔洞水库目前存在的主要食鱼性鱼类为鲇, 但其在渔获物中的数量比例仅为 $0.09 \%$, 重量比例也仅为 $0.11 \%$ (表 1), 并且其主要分布于水体底层. 根据本研究, 渔洞水库 $97.4 \%$ 的鱼类分 布于水体的表层, 小型鱼类与鲇在空间生态位上存在差异, 因此仅仅依靠鲇无法控制水库中的小型鱼类, 需 在加大对银鱼资源捕捞力度的基础上, 引人其他食鱼性鱼类. 有鉴于此, 渔洞水库及其他水环境及鱼类群落 结构与此类似的高原水库在考虑采用经典生物操纵途径时,引进食鱼性鱼类时需充分考虑其空间生态位, 使其与被捕食鱼类的空间生态位具有较高的重叠度. 此外, 考虑到外来物种人侵, 建议从水库所属水系引人 符合以上标准的鱼类.

\section{4 参考文献}

[ 1 ] Shen KX, Shen SB, Song DE. Analysis on cause of $\mathrm{pH}$ anomaly of Yudong Reservoir and suggestions for water resources protection. Environmental Protection and Technology, 2004, 20(1):34-45. [ 申开旭, 申时斌, 宋大恩. 渔洞水库 $\mathrm{pH}$ 值异常成因分析及水资源保护建议. 环保科技, 2004, 20(1):34-45.]

[ 2 ] Zhao QR, Li QB. Research on water quality pollution and control of Yudong Reservoir. Yunnan Environmental Science, 2006, 25 (supplement) : 79-81. [赵启荣, 李清报. 渔洞水库水质污染与防治研究. 云南环境科学, 2006, 25 (增 刊): 79-81.]

[ 3 ] Wu WJ, Yang K, Wang ZC et al. Community structure and seasonal succession of phytoplankton in Yudong Reservoir of Yungui-plateau. Journal of Hydroecology, 2012, 33(2) : 69-75. [ 吴卫菊, 杨凯, 汪志聪等. 云贵高原渔洞水库浮游植 物群落结构及季节演替. 水生态学杂志, 2012, 33(2) : 69-75.]

[ 4 ] Dai TG. Water quality research and status evaluation in Yudong Reservoir. Journal of Water Resources Research, 2013,34 (2) : 39-46. [代堂刚. 渔洞水库水质研究与现状评价. 水资源研究, 2013, 34(2) : 39-46.]

[ 5 ] Li XY, Song LR, Liu YD. The production, detection and toxicology of Microcystins. Acta Hydrobiologica Sinica, 1999, 23 (s1) : 517-523. [李效宇, 宋立荣, 刘永定. 微囊藻毒素的产生、检测和毒理学研究. 水生生物学报, 1999, 23 ( s1) : 517-523.]

[ 6 ] Xie P ed. Microcystins in aquatic animals with potential risk to human health. Beijing: Science Press, 2006. [谢平. 水生 动物体内的微囊藻毒素及其对人类健康的潜在威胁. 北京: 科学出版社, 2006.] 
[ 7 ] Liu JK, Xie P. Direct control of microcystis bloom through the use of Planktivorous Carp-closure experiments and lake fishery practice. Ecologic Science, 2003, 22(3): 193-196. [刘建康, 谢平. 用鲢鳙直接控制微囊藻水化的围格实验和湖 泊实践. 生态科学, 2003, 22(3): 193-196.]

[ 8 ] Godlewska M, Swierzowski A, Winfield IJ. Hydroacoustics as a tool for studies of fish and their habitat. Ecohydrology Hydrobiology, 2004, 4: 417-427.

[ 9 ] Simmonds EJ, MacLennan DN. Fisheriesacoustics: Theory and practice. Oxford: Blackwell Science, 2005.

[10] Lian YX, Ye SW, Godlewska M et al. Diurnal, seasonal and inter-annual variability of fish density and distribution in the Three Gorges Reservoir (China) assessed with hydroacoustics. Limnologica, 2017, 63: 97-106.

[11] Dai TG, Song ZY. Study on hydrological change in Yudong Reservoir. Journal of Water Resources Research, 2014, 35(2) : 20-24. [代堂刚, 宋昭义. 渔洞水库水文变化情势研究. 水资源研究, 2014, 35(2) : 20-24.]

[12] Zhang L, Duan QC, Wang J et al. Study on permissible pollution bearing capacity of water bodies for Yudong Reservoir. Water Resources and Power, 2014, 32(6) : 45-48. [张雷, 段琪彩, 王杰等. 渔洞水库水体纳污能力研究. 水电能源 科学, 2014, 32(6): 45-48.]

[13] Duncan A, Kubecka J. Hydroacoustic methods of fish surveys. Bristol: National Rivers Authority, 1993.

[14] Kubecka J, Duncan A. Diurnal changes of fish behaviour in a lowland river monitored by a dual-beam echosounder. Fisheries Research, 1998, 35(1): 55-63.

[15] Lyons J. A hydroacoustic assessment of fish stocks in the River Trent, England. Fisheries Research, 1998, 35(1) : 83-90.

[16] Ye S, Lian Y, Godlewska M, Liu JS et al. Day-night differences in hydroacoustic estimates of fish abundance and distribution in Lake Laojianghe, China. Journal of Applied Ichthyology, 2013, 29(6) : 1423-1429.

[17] Foote KG, Knudsen HP, Vestnes G et al. Calibration of acoustic instruments for fish density estimation: A practical guide. Cooperative Research Report No. 144. International Council for the Exploration of the Sea, Copenhagen, Denmark, 1987 : 1-69.

[18] Aglen A. Random errors of acoustic fish abundance estimates in relation to the survey grid density applied. FAO Fisheries Report, 1983, 300: 293-298.

[19] Doroszczyk L, Długoszewski B, Godlewska M. Comparison of acoustical estimates of fish abundance for different coverage and survey design. Hydroacoustics, 2007, 10: 33-38.

[20] Godlewska M, Długoszewski B, Doroszczyk L et al. The relationship between sampling intensity and sampling error-empirical results from acoustic surveys in Polish vendace lakes. Fisheries Research, 2009, 96(96) : 17-22.

[21] Chen YY ed. Fauna Sinica, Osteichthyes, Cypriniformes II. Beijing: Science Press, 1998: 102-448. [陈宜瑜. 中国动物 志硬骨鱼纲鲤形目 (中卷). 北京: 科学出版社, 1998: 102-448.]

[22] Yue PQ ed. Fauna Sinica, Osteichthyes, Cypriniformes III. Beijing: Science Press, 2000: 391-433. [乐佩琦. 中国动物 志硬骨鱼纲鲤形目 (下卷). 北京: 科学出版社, 2000: 391-433.]

[23] Chu XL, Chen YR eds. Fishes of Yunnan Province (Volume 1). Beijing: Science Press, 1989: 40-350. [褚新洛, 陈银 瑞. 云南鱼类志 (上册). 北京: 科学出版社, 1989: 40-350.]

[24] Chu XL, Chen YR eds. Fishes of Yunnan Province (Volume 2). Beijing: Science Press, 1990: 5-253. [褚新洛, 陈银 瑞. 云南鱼类志 (下册). 北京: 科学出版社, 1990: 5-253.]

[25] De'ath G. Multivariate regression trees: a new technique for modeling species-environment relationships. Ecology, 2002, $\mathbf{8 3}(4)$ : 1105-1117

[26] Breiman L, Friedman JH, Olshen RA et al. Classification and regression trees. Wadsworth International Group, Belmont, California, USA, 1984.

[27] Team RC. R: A language and environment for statistical computing. R Foundation for Statistical Computing, Vienna, Austria. Available at: http://www.R-project.org/.2013.

[28] Ouellette MH, Legendre P, Borcard D. Cascade multivariate regression tree: a novel approach for modelling nested explanatory sets. Methods in Ecology and Evolution, 2012, 3(2) : 234-244.

[29] Frouzova J, Kubecka J, Balk H et al. Target strength of some european fish species and its dependence on fish body parameters. Fisheries Research, 2005, 75(1/2/3) : 86-96.

[30] Zhang TL. Life history strategies, trophic patterns and community structure in the fishes of Lake Biandantang[Dissertation]. Wuhan: Institute of Hydrobiology, Chinese Academy of Sciences, 2005: 75-117. [张堂林. 扁担塘鱼类生活史策 
略、营养特征及群落结构研究 [ 学位论文]. 武汉: 中国科学院水生生物研究所, 2005: 75-117.]

[31] Liu ES, Bao CH, Wu LK et al. Comparison of food composition and analysis on mutual effects between Neosalanx tangkahkeii taihuensis Chen and Coilia ecten taihuensis Yen et Lin in Lake Taihu. J Lake Sci, 2007, 19(1) : 103-110. DOI: 10. 18307/2007.0116. [刘恩生, 鲍传和, 吴林坤等. 太湖新银鱼、鲚鱼的食性比较及相互影响分析. 湖泊科学, 2007, 19(1) : 103-110.]

[32] Prchalova M, Kubecka J, Cezh M et al. The effect of depth, distance from dam and habitat on spatial distribution of fish in an artificial reservoir. Ecology of Freshwater Fish, 2009, 18(2) : 247-260.

[33] Jeppesen E, Jensen JP, Sodergaard M et al. Response of fish and plankton to nutrient loading reduction in eight shallow Danish lakes with special emphasis on seasonal dynamics. Freshwater Biology, 2005, 50 : 1616-1627.

[34] Garcia XF, Diekmann M, Bramick U et al. Correlations between type-indicator fish species and lake productivity in German lowland lakes. Journal of Fish Biology, 2006, 68: 1144-1157.

[35] Wang CM, Li LQ, Zhang JQ et al. The preliminary survey on macroinvertebrate community structure and its relationship with environmental factors in Yudong Reservoir. Freshwater Fisheries, 2015,(2): 37-42. [王丑明, 李利强, 张君倩等. 渔洞水库大型无脊椎动物群落结构及其与环境关系的初步调查. 淡水渔业, 2015, (2) : 37-42.]

[36] Fernando CH, Holcik J. Fish in reservoirs. Internationale Revue Gesampten Hydrobiologie, 1991, 76: 149-167.

[37] Yin MC ed. Fish echology. Beijing: Agricul ture Press, 1995: 40-42. [殷名称. 鱼类生态学. 北京: 中国农业出版社, 1995: 40-42.]

[38 ] Dai TG. Analysis on the influence of seasonal variation on water temperature and water quality of Yudong Reservoir. Journal of Water Resources Research, 2008, (4) : 15-17. [代堂刚. 季节变化对渔洞水库水温、水质的影响分析. 水资源研究, 2008, (4): 15-17.]

[39] Brosse S, Lek S, Dauba F. Predicting fish distribution in a mesotrophic lake by hydroacoustic survey and artificial neural networks. Limnology and Oceanography, 1999, 44(5): 1293-1303.

[40] Miranda LE, Killgore KJ. Fish depth distribution in the lower Mississippi River. River Research \& Applications, 2014,30 (3) : 347-359.

[41] Neal JW, Prchalová M. Spatiotemporal distributions of Threadfin Shad in Tropical Reservoirs. North American Journal of Fisheries Management, 2012, 32: 929-940.

[42] He DR, Cai HC eds. Fish behaviors. Xiamen: Xiamen University Press, 1998. [何大仁, 蔡厚才. 鱼类行为学. 厦门: 厦门大学出版社, 1998.]

[43] Shapiro J, Lamarra V, Lynch M. Biomanipulation: An ecosystem approach to lake restoration. Proceedings of the Symposium on Water, 1975, 21(6) : 85-96.

[44] Hansson LA, Bergman E, Annadotter H et al. Biomanipulation as an application of food chain theory constraints, synthesis, and recommendations for temperate lakes. Ecosystems, 1998, (1) : 558-574.

[45] Liu JK, Xie P. Unraveling the enigma of the disappearance of water bloom from the East lake (Lake Donghu) of Wuhan. Resources and Environment in the Yangtze Basin, 1999, 8(3):312-319. [刘建康, 谢平. 揭开武汉东湖蓝藻水华消失 之迷. 长江流域资源与环境, 1999, 8(3): 312-319.]

[46] Xie P, Liu JK. Practical success of biomanipulation using filter-feeding fish to control cyanobacteria blooms: A synthesis of decades of research and application in a sub-tropical hypereutrophic lake. The Scientific World, 2001, (1) : 337-356. 